\title{
The Largest, Metropolitan, and Global Centers in the World Arena: Matching Networks
}

\author{
A. I. Treivish* \\ Institute of Geography, Russian Academy of Sciences, Moscow, 119017 Russia \\ *e-mail: trene12@yandex.ru
}

Received April 22, 2021; revised June 14, 2021; accepted July 16, 2021

\begin{abstract}
The article compares the leadership of the world's cities in terms of their size, capital status, global economic functions, and spatial structure of their networks. The global network of 210 largest centers is polycentric but coincides with the network of capitals by only one-third. Giant countries, except for Indonesia and Russia, are characterized by bi- or even polycentrism and active competition of the leading cities. They are dictated by geographic, political, and other factors. Smaller countries, far more numerous in the world, as a rule (but not without exceptions), have monopolistic centers, most often represented by their capitals as absolute and unrivaled leaders. Lists of just large and global cities almost equal in length coincide by $60 \%$. It is difficult for small and poor countries to create global centers; it is easier for them to grow a global center from a capital or largest city. Shifts of urban networks to the south at the planetary level are caused by both global and (often) internal forces, including sharp reversals in countries with transitional economies.
\end{abstract}

Keywords: center, leader, geographic (calculated) center, city size, global city, capital city, city network, spatial shift

DOI: $10.1134 /$ S2079970521040171

\section{INTRODUCTION}

Modern spatial development, among other things, is distinguished by the shift of problems previously considered regional, national, and global, to the level of metropolitan, global, or simply major cities. These are arenas of cooperation and rivalry, manifestations of the positive and negative effects of urbanization, places for the efforts of politicians and sustainable development programs. ${ }^{1}$ Such centers and their networks determine the power geometries, termed by D. Massey (1999).

Macrogeography of urban networks seems to be well studied. The relevant literature is immense. Its review is inappropriate here, especially since the reviews were issued and included the concepts important for this article such as network, megacity (metropolis), agglomeration and conurbation, world, and global city (Glezer et al., 2014). Academic "fashion" generally shifts from the work of individual authors to collective reviews with unified approaches (e.g., based on the Global Human Settlement system), big data, etc., or analysis of problems specific to individual cases. However, it is too early to close the "traditional" line. First, urban networks are volatile: some centers

\footnotetext{
${ }^{1}$ World Cities Report 2020 / UN-Habitat. Nairobi, 2020. https://unhabitat.org/sites/default/files/2020/10/wcr_2020_report.pdf.
}

grow and flourish, while others stagnate and lose their former positions. Second, cities are full of acute contradictions. In cities with 50000 or more inhabitants, employment, mobility and living standards are higher than in towns and semidense areas, not to mention rural areas, but there are increasing risks to the environment, health (the COVID-19 pandemic is mainly an urban crisis), street crime and other security problems, transport, etc. ${ }^{2}$ Third, information gaps and controversial issues remain.

For instance, the leadership (supremacy, primacy) and centrality of cities are manifested in different spheres and signs, and it is hard to say in advance which of them is more important. The city is surely the "center," but the center of what? Geographers distinguish between two types of centers. ${ }^{3}$ The first type, on which the theory of central places is based, comprises the centers of compact territories (zones) and their services; the larger the cities, the larger the zones, as a rule. The second type is represented by the centers of a particular activity. The networks of such specialized centers are arranged differently, and their role is lim-

\footnotetext{
${ }^{2}$ OECD/European Commission Cities in the World: A New Perspective on Urbanization / OECD Urban Studies. Paris: OECD Publishing, Paris, Revised version, June 2020. 169 p. https://doi.org/10.1787/d0efcbda-en.

${ }^{3}$ Classic researchers wrote about these: Walter Isard, Peter Haggett, G.M. Lappo (Lappo, 1997, pp. 84-89; etc.).
} 
ited to some requirement. Instead, even a small center can have an extensive market zone. In addition, the third type of centrality is important for geography: the position of a city in a certain part of the space, taking into account (or not taking into account) its uneven development. Analysis of the centrality of large cities is complicated by the fact that they combine different and hardly-splitable types.

The capital city is a special kind of a center on a national scale, i.e., of the first type, although it also has features of the second, since we are talking about a command political and administrative function. Sometimes regional, as well as economic or cultural, centers are called not strictly capitals: Los Angeles (Hollywood) is referred to as the "capital" of the American and global film industry, Frankfurt am Main as the "financial capital" of Germany and the EU, Milan as the "capital of fashion," etc. A state normally has only one official capital but may also have several informal ones. Scientists continue to be interested in capitals (Okunev, 2020; Orttung, 2019; Rossman, 2016; etc.), but little attention is paid to their relations with their own kind and with networks of other groups of centers.

Centers similar in size and function, just like others, compete on the world stage, within countries, and their regions. This is an immanent property of centers of the second type, although it also applies to the first, including capitals, whose hostility or friendship is more often determined by relations between countries. Among the functional centers, global cities (key points of the postindustrial world economy) stand out. With the weakening of globalization in recent years, these remain conductors for international links, sometimes no less than capitals, even in terms of their political role, but more indirectly. Since 1998, they have been studied by the Globalization and World Cities Research Network (GaWC), founded by Peter J. Taylor (2003), which regularly publishes its reports and lists of cities.

This article covers three types of centrality and leadership: size (population), status (capitals of states), and global functions (world cities); it also addresses the structure of their networks. The main objective is to compare the global lists of leading cities with lists of national capitals and global centers for their coincidence or mismatch, monocentric or polycentric nature, and the presence or absence of at least potential competition. Such an analysis is useful in studying alternatives to urban and, in addition, regional, national, and global development. The geographic centrality of urban networks on a planetary scale and some national ones is touched upon at the end of the article using centrography methods.

\section{MAJOR CITIES IN THE WORLD: FEATURES,} DATA, AND NETWORK DYNAMICS

The key parameter of a city is its size. First of all, the number of inhabitants (understood below by the word "size"), and not the area, production volume, or cultural weight, although they are important in their own right. At the same time, it is explicitly or implicitly believed that a city gathers population for a reason, because its "mass" is a feature of the importance of a place (center) and functions (role in society). However, the functions differ in terms of labor intensity, which affects the size of the city; they react differently to the proximity of competitors and other externalities. Therefore, cities of different sizes often perform the same function, and equality of size does not mean similarity of roles.

A particular problem relates to the boundaries within which the population of the centers is confined. Their administrative framework differs in each country and even in each case. Many giants have long outgrown their official frame, but since some time, they have not changed it. Paris has retained the same boundary since 1860; New York, since 1898; Tokyo, since 1943, when the metropolitan area absorbed 23 separate municipalities (the former city) and 26 other cities, 1 county, and 4 administrative districts with 13 settlements. All of this is, in fact, one "body." The structures of large cities in China and, more recently, in Russia is no less difficult. The boundaries of some cities move with the actual sprawl, albeit not quite adequately. Moscow is a vivid example. Its last expansion in 2012 increased the area of the city by 2.4 times, moving it up five places in the world ranking on this basis, but not increasing its place in terms of population, since "New Moscow" encompassed only a fraction of the capital's suburbs.

A solution is seen as a transition to urban agglomerations, which in the West, especially in the Englishspeaking world, are identical to metropolitan areas (MA). They are often called functional cities, but these are not the functions of a core city in the country or the world. The term refers to the functioning of a commuting zone (daily labor market) with bedroom and other suburbs augmenting the cores with their main specialization.

After some hesitation, the author of the article chose a certain middle option: urban areas (UA) with continuous built-up, or a physical city, according to a yearbook published 16 years in a row. ${ }^{4}$ Its estimates are based on country statistics or on a small area (resolution $250 \mathrm{~m}$ ) of the European Commission Global Human Settlement population grid GHS2015. It is considered that a UA is smaller than an MA, which covers separated built areas, like in the case of Paris (Fig. 1). Here, the MA consists of 412 UA municipal-

\footnotetext{
${ }^{4}$ Demographia/World Urban Areas. 16th Annual Edition, 2020. 2020.04. http://demographia.com/db-worldua.pdf.
} 
ities, including the Paris department itself, and 1386 rural and urban ex-UA units.

Sometimes the built-up area can go beyond the MA and exceed its population, but usually these dimensions are of the same order of magnitude, larger than those of cores, which also soften the effect of different administrative boundaries. The city of Paris is inferior to Beijing by an order of magnitude in terms of population and 156 times in area, while their UAs differ in both features by less than half. Like MAs, they can have two or more cores. ${ }^{5}$ The data are presented for 1055 UA with 500000 residents or more as of 2019. In total, this is 2.25 bln people, $29 \%$ of the world population and $51.4 \%$ of the urban population.

The dynamics of the UA is not addressed by the yearbook, but it roughly corresponds to the dynamics of cities and agglomerations, regularly detected by other sources. ${ }^{6}$ In short, since the 1970s, there have been two 50-year trends:

(1) The number of urban dwellers in the world has doubled and continues to grow, exceeding $50 \%$ of the total population: the UN "appointed" 2007 as the transition date. People move from small settlements to major ones and their clusters. In 2019, 72-73\% of city dwellers lived in large cities (100 000 people or more), including $44 \%$ in million-plus and $15 \%$ in megacities of $10 \mathrm{mln}$ or more. The growth of population in all these centers resulted from half the densification within the original city limits; one fourth from doubling of the number of centers and one-fourth from their sprawl. Meanwhile, one-fifth of MAs have contracted in population since 2000 . The process was driven by intra- and intercountry migration. This is also the reason for the growth in ethnocultural diversity of megalopolises.

(2) High-income countries concentrate larger shares of their population in large and very large urban centers but lower shares in smaller areas. The share of people living in million-plus MAs is roughly four times higher in high-income $(47 \%)$ than in lowincome (12\%) countries. Usually, the richer a country (group of countries), the higher the share of the MA's commuting suburban zone. However, the "pressure" of the global South and East population on their MAs

\footnotetext{
${ }^{5}$ An example is the Essen-Dusseldorf UA on an area of $2684 \mathrm{~km}^{2}$ (slightly larger than today's Moscow) and with a population of $6.1 \mathrm{mln}$ people, clearly encompassing all the cities of Regionalverband Ruhr. In the yearbook, they are labeled as combined, and their composition is selectively explained by a separate table "Specific Urban Areas," where transboundary UAs are also noted.

${ }^{6}$ OECD/European Commission Cities in the World: A New Perspective on Urbanization / OECD Urban Studies. Paris: OECD Publishing, Paris, Revised version, June 2020. 169 p. https:// doi.org/10.1787/d0efcbda-en; World Cities Report 2020/UNHabitat. Nairobi, 2020. https://unhabitat.org/sites/default/ files/2020/10/wcr_2020_report.pdf; Moreno-Monroy et al., 2020; etc.
}

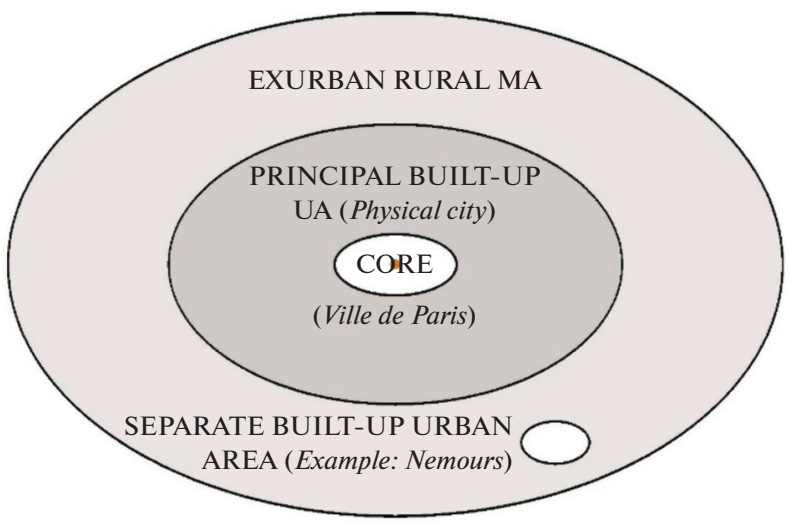

Fig. 1. Urban areas and metropolitan areas: contrast example of Paris.

Compiled from Demographia/World Urban Areas. 16th Annual Edition, 2020. $2020.04 \quad$ (http://demographia.com/db-worldua.pdf) with author minor corrections.

is so great that the latter are growing faster than their counterparts in the global North and West.

Let us now discuss the distribution of UAs by size, region, and country. At the global level, it is purely polycentric. The real Zipf's line lies above the ideal straight line, and detachment from it on a logarithmic scale increases with the rank number (Fig. 2). This, by the way, is the difference from the distribution of countries by number of their citizens, following mainly Zipf's law, although India and China deviate upward, and small countries (with populations smaller than the Netherlands), downward.

The national systems are different. According to many experiments, US cities within their official framework lie quite well on the Zipf's line. The line of UAs is flatter; their populations differ less than prescribed by the theory. This also applies to India and, particularly China. However, in Indonesia and Russia, leaders rise strongly above other UAs. The ratios of the first UA population to its total in the next three are suggested instead of cumbersome graphs. Globally, this is 0.43 , and on average, the ten most populous countries have 1.1 (ideally, it should be 0.92 ) owing to Russia and Indonesia, where the indicators are higher than 2.0; in China, 0.39; in India, 0.54; in the USA, 0.65; and in Pakistan, 0.77.

Tokyo still leads among UAs worldwide, followed by Jakarta, Delhi, Mumbai, and Manila. China's first, Shanghai, is only sixth; Gaunzhou-Foshan is tenth; and Beijing is 12th, partly due to the long struggle against the inflow of migrants. São Paulo placed seventh; Mexico City, ninth; and New York, 11th (the leader in area, closing the list of UAs with $20 \mathrm{mln}$ people). Moscow is in 15th place; St. Petersburg, 86th.

The change in "first placers" is indicative (in the 20th century these are MAs leading in population): 


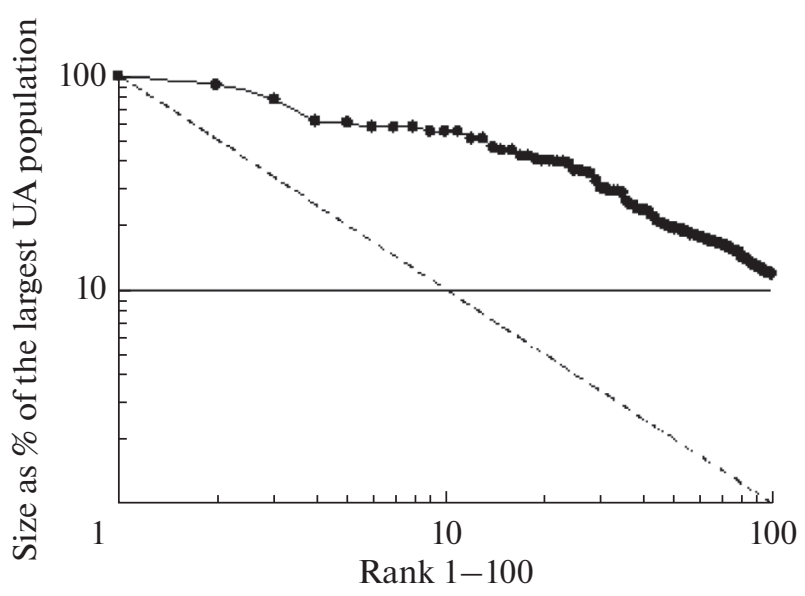

Fig. 2. Rank-dimensional distribution of 100 world largest urbanized areas: $\log -\log$ graph.

Compiled from data of Demographia/World Urban Areas. 16th Annual Edition, 2020. 2020.04 (http://demographia.com/db-worldua.pdf).

1950, New York; 1990, Mexico City; 2020, Tokyo. ${ }^{7}$ These and other shifts that changed the hierarchy did not eliminate the differences in development and urbanization between the old Western UAs and their new Third World rivals (Table 1). In their number and total population size, the share of Asia, not to mention Africa, is lower than their share in the global population. In both Americas, the relationship is the opposite. In Europe, where UAs are relatively small, evidenced by their number and population size, the latter coincides with the share in the global population.

\section{WORLD'S LARGEST CITIES AND CAPITALS OF COUNTRIES: A COMPARISON}

For comparison, out of 1055 UAs, 210 were chosen with populations of at least $2.4 \mathrm{mln}$. Their number is close to the that of capitals and global cities. These are UAs from 77 countries, of which China has 41; the USA, 20; India, 17; etc. (Fig. 3). 60 countries, including Russia, have one to two UAs. National capitals serve as cores or are part of 72 UAs, i.e., a third of them. Such a weak coincidence of networks is caused by their fundamentally different structures: normally, a country of any size has one capital, while the number of major centers depends on the nation's size and economic strength. The correlation coefficient between this number and the population of 30 countries with two or more UAs from the list of 210 is 0.85 , and with the volume of GDP (PPP), 0.89; the relationship with the area of territory is much weaker, 0.42 . If we add the largest national UAs without capital status (there are

\footnotetext{
${ }^{7}$ Based on date of the cited years. Within the current MA framework, Tokyo could have bypassed New York by 1960, although it has remained a leader ever since, albeit more easily accessible to new Asian rivals.
}

20 in the list) to the capitals, then their total share will increase to $43 \%$, which again is not much.

Figure 4 individually shows the global network of large UAs and alignment of its centers with capitals and leaders in the settlement pattern of countries. Clustering of UAs is visible in East and South Asia, in some places in America and in Africa (on the Guinean coast), but not in Europe, where there are few giant cities by current standards. In vast and populous countries with an abundance of large centers, national leaders are a minority. And where the political map is more colorful, as in Central America, the capitals form large UAs. However, this also depends on the type of the capital center.

Capitals vary in size and range of functions. More than 30 years ago, the author tried to reduce their diversity to three types, later refining them (Moskovskii..., 1988, pp. 13-15; Treivish, 2009, pp. 306-307; Treivish et al., 2014):

(1) absolute (exclusive) leaders with no real rivals inside the country equal in size and other major attributes;

(2) relative leaders equal to other center(s), and in some key areas, inferior;

(3) narrow-political leaders that emerged in the form of: (a) compromise between competing areas and centers; (b) a stimulator for internal spatial development or external relations; (c) the consequence of sharing power with other centers.

There are some controversial cases. For example, if close conurbation dominates in a country where metropolitan functions are dispersed, as in the Dutch Randstad, ${ }^{8}$ then the capitals included in it can be attributed either to type 1 or $3 \mathrm{c}$. Over time, the type can change and evolve. Russia's St. Petersburg was first the leader of type $3 b$, then type 2 (the country had, in fact, two capitals), until the monopoly of Moscow eliminated internal competition. Today its UA is 3.3 times larger than that of St. Petersburg, and the transfer of some federal bodies to Russia's "northern capital" has changed little. Clearly, only capitals of types 2 and 3 have real rivals, leaders of the settlement pattern and/or economy in their countries.

The previous attempt to classify the official capitals of the 159 not smallest countries (Treivish et al., 2014) identified $76 \%$ of them as type 1 . However, the share of such countries in population is half as much, and $53 \%$ of humans lives in countries with type 2 capitals: China, India, Pakistan, Canada, USA, Australia, etc. Indonesia and Russia are the exceptions among giants. Leaders of type 3 (6\% in countries with $10 \%$ of the world population) were found in Switzerland, many former possessions of Britain (but not in itself, where

\footnotetext{
${ }^{8}$ In the list of UAs, in contrast to the German Ruhr, it is represented by three areas: Rotterdam-Hague, Amsterdam, and Utrecht. Amsterdam is regarded as the official capital, but the main government is in the Hague.
} 
Table 1. Urban areas in the world and its major regions, 2019

\begin{tabular}{l|r|r|c|c|c}
\hline \multirow{2}{*}{ Region } & \multicolumn{2}{|c|}{ UAs } & \multicolumn{2}{c|}{ UAs' population } & \multirow{2}{*}{ Total population, \% } \\
\cline { 2 - 5 } & number & $\%$ & mln people & $\%$ & 100.0 \\
\hline World & 1055 & 100.0 & 2250.2 & 100.0 & 59.5 \\
Asia* & 571 & 54.1 & 1270.8 & 56.5 & 9.6 \\
Europe** $_{\text {North America*** }}$ & 150 & 14.2 & 216.2 & 9.6 & 4.7 \\
South America & 127 & 12.0 & 287.1 & 128 & 5.5 \\
Africa & 74 & 7.0 & 180.5 & 8.0 & 17.2 \\
Oceania & 126 & 11.9 & 279.1 & 12.4 & 0.5 \\
\hline
\end{tabular}

* Including Istanbul; ** including UAs of Russia; *** including Central America and Caribbean.

Compiled from Demographia/World Urban Areas. 16th Annual Edition, 2020. 2020.04 (http://demographia.com/db-worldua.pdf).

London is attributed to type 1) and when the capital is not very old: in Brazil, Nigeria, Tanzania, Kazakhstan, and Myanmar.

$\mathrm{Bi}$ - or even polycentrism of urban networks in large countries is often associated with their multi-regionalism and long-standing rivalry between regions: the North and South of the United States, China, India, Pakistan, and English and French-speaking Canada (Toronto vs. Montreal). ${ }^{9}$ In countries with a transcontinental, interoceanic position, such as the USA, Canada, and Australia, where Sydney is opposed by Melbourne, with Canberra, like Ottawa, located between them, regions and centers of different coasts compete. For smaller countries, this is less typical, and it is their abundance in the world that determines the predominance of type 1 capitals: absolute leaders unopposed.

All this affects the relationship between the populations of countries and their capitals, which can be seen in the graphs (Fig. 5), especially in the upper parts of the curves. In countries with type 1 capitals, the dependence is generally weaker, and after Tokyo, their size generally ceases to respond to the demographic mass of the country, which does not exceed $270 \mathrm{mln}$ with full leadership of the capital (Indonesia). For types 2 and 3, the line from Washington goes to Beijing and Delhi-the relative leaders of giant Asian countries with an unattainable number of citizens (together they make up more than a third of the world's population).

Earlier, we tried to figure out how urban leaders were located with respect to the borders and seacoasts of 178 countries ( 45 have centers competing with capitals). The distances from the center to the nearest point of the country's outline was measured as both

\footnotetext{
${ }^{9}$ This is competition in all spheres: economic (for investment, the best personnel, tourist flows, etc.), cultural, including events (for entry into lists of heritage sites; holding of festivals, exhibitions, and championships), political (localization of relevant bodies and organizations, forums, and summits, placing in various ratings, development programs, etc.), and in the cognitive sphere mediating others (branding and struggle for a better image).
}

absolute and relative to the length of the reduced radius ( $R R$, the radius of a circle equal to the country in terms of area). Referring to (Treivish, 2016) for details, let us mention the main results.

The average distance of capital cities was $70 \mathrm{~km}$ and $20 \%$ RR. Brasília (920 km to the ocean), Moscow, and Addis Ababa (398-400 km to the land borders) were most remote. A distance up to $50 \mathrm{~km}$ was noted in $63 \%$ of countries, more often coastal ones. In 40 landlocked states, the capitals were "deepened" by an average of $26 \%$ of the RR, and in 138 with access to the sea, by $18 \%$. The absolute distance correlates with the country size, but not the relative distance, with its maximum in Addis Ababa (67\% RR). Seventy-five capitals had a distance up to $10 \% \mathrm{RR}$, and 41 , borderline in fact, had less than $1 \%$. The informal leaders in 45 countries are more extroverted than capitals in terms of location: $7 \%$ RR versus $20 \%$, and even $6 \%$ relative to the sea. The modest figures are partly related to the noncompact form of countries, but still raise doubts about the correctness of the classic researchers, who noted the gravitation of capitals to the inner parts, if not to the geographical centers of national territories. However, comparison with other MAs of some large countries (not only the clear rivals of capitals) showed that the capitals are usually farther from the borders.

Concluding this part of the article, let us reiterate that countries powerful in all respects generally possess bi- and polycentric urban systems due to geographic and political factors, such as their regions' multiplicity and competition. In smaller countries, this is rather an exception and the monopoly of the center leader, the rule, which limits the alternatives of spatial development. Small and medium-sized countries are numerous, thus providing an abundance of type 1 capitals (absolute national leaders) in the world. 


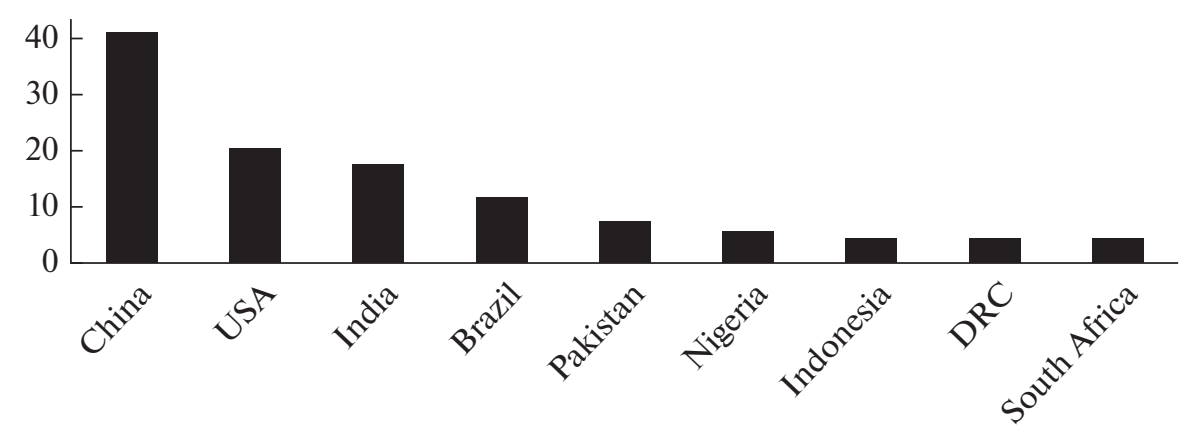

Fig. 3. Number of UAs (out of 210 largest in the world) in leading countries.

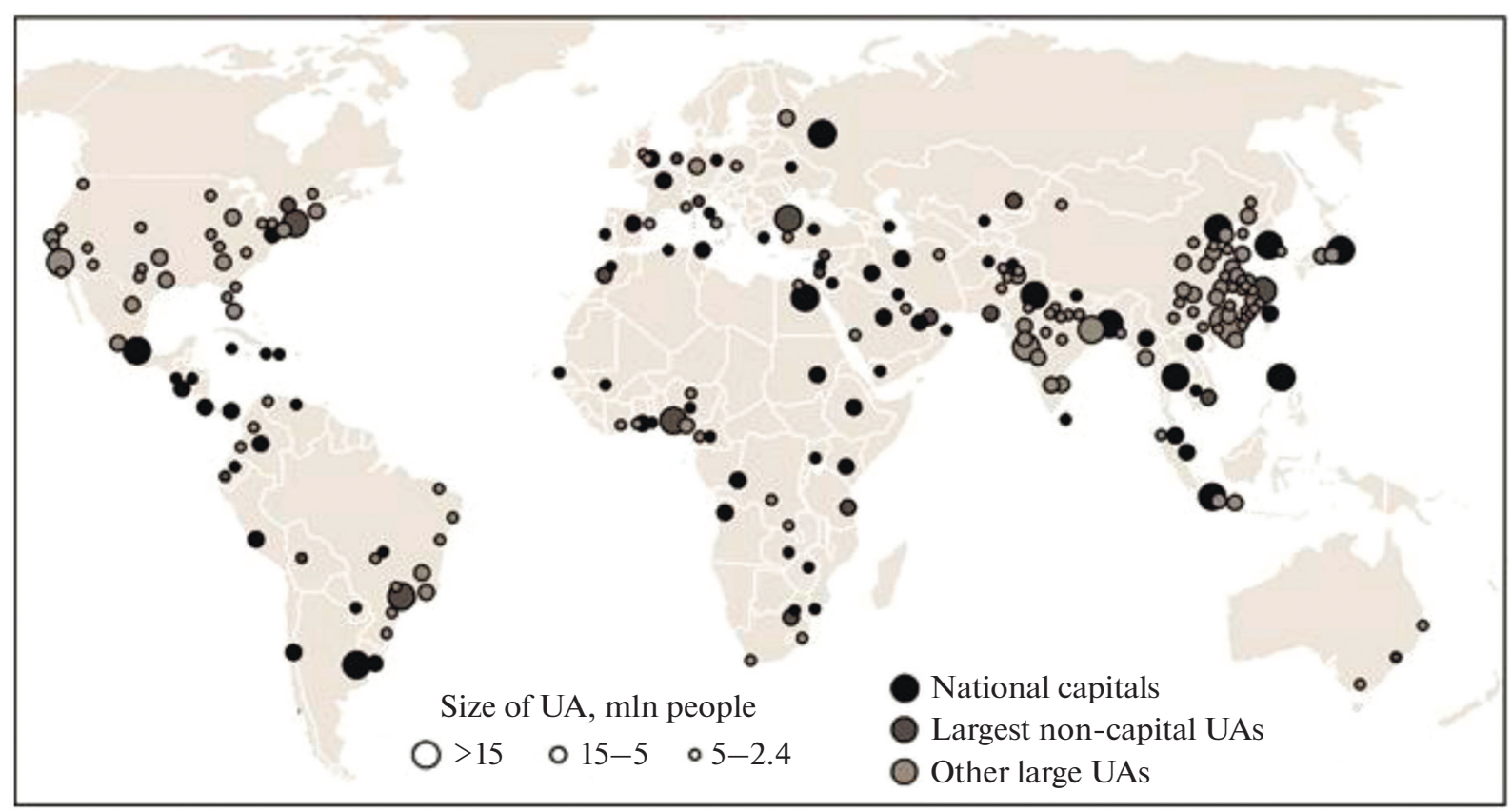

Fig. 4. Largest urbanized areas (210 UAs) in 2019 and national leaders among them.

\section{GLOBAL CENTERS: NETWORK AND COMPARISONS WITH URBAN AREAS AND CAPITALS}

In 2018, there were 209 global cities (GCs), nodes of the modern economy's supporting frame. ${ }^{10}$ Actually, GCs are divided into the classes $a, \beta$, and $\gamma$ and subclasse, denoted by "+" or "-" or their absence (no mark) for the "average" representatives of the classes. We omit another 152 centers with sufficient business services, which reduces dependence on GCs. ${ }^{11}$

\footnotetext{
${ }^{10} \mathrm{GaWC}$ city link classification 2018. Lboro.ac.uk. November 13 , 2018. Accessed August 7, 2019. https:// www.lboro.ac.uk/gawc/world2018link.html.

${ }^{11}$ Of the Russian cities, Novosibirsk is listed among them, and the list of GCs as such includes Moscow (class $\alpha$ ) and St. Petersburg (class $\gamma$ ).
}

The overlap with the list of 210 UA reaches $60-$ $61 \%$; i.e., it occurs almost twice as often as between UA and national capitals. The top 25 largest UAs are all GCs. At the same time, the list of 210 UAs lacks 12 GCs of class $a, 32$ of class $\beta$, and 34 of class $\gamma$. For GCs, size is actually not that important. Luxembourg and Port Louis in Mauritius would have been just big in Russia (100000-200000 people), and Georgetown in the British Caymans falls short of an average Russian city. Luxembourg, meanwhile, is the city of subclass $a-$, and island tourist and financial harbors, the $\beta$-cities.

GCs still correlate with population size. The a centers are 2.3 times larger than $\beta$, and the latter are 1.3 times larger than those of class $\gamma .^{12}$ The trend towards a decrease in the average size with the GC status is disrupted at the edges of the main classes, especially between subclasses $\beta$ - and $\gamma+$ (Fig. 6). Perhaps, 
(a)

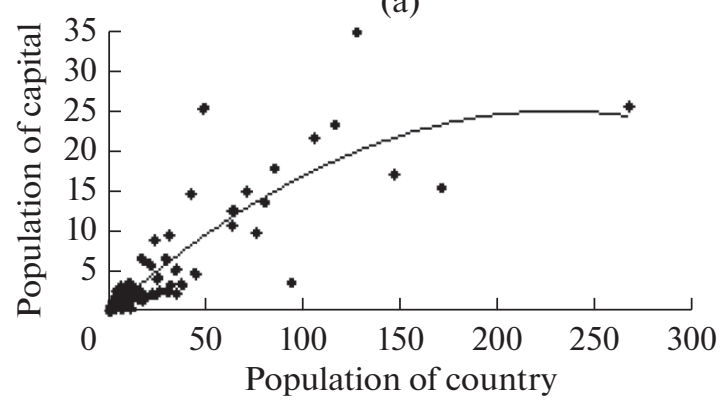

(b)

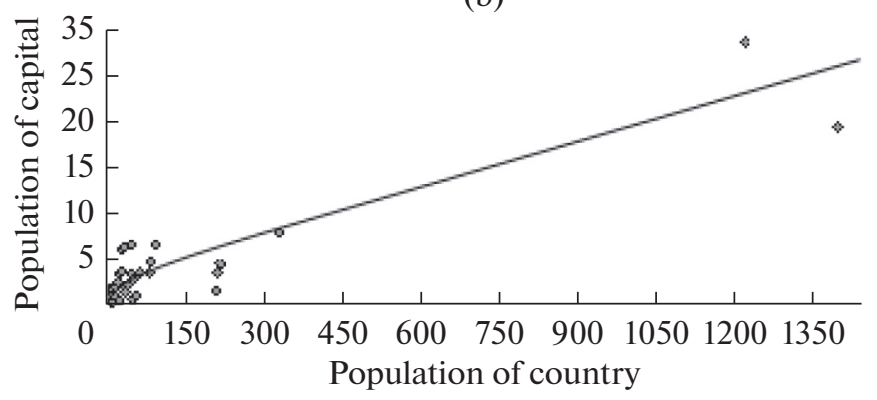

Fig. 5. Relationship between populations of countries and their official capitals around 2015, mln people: (a) absolute leaders; (b) relative and unilateral political leaders.

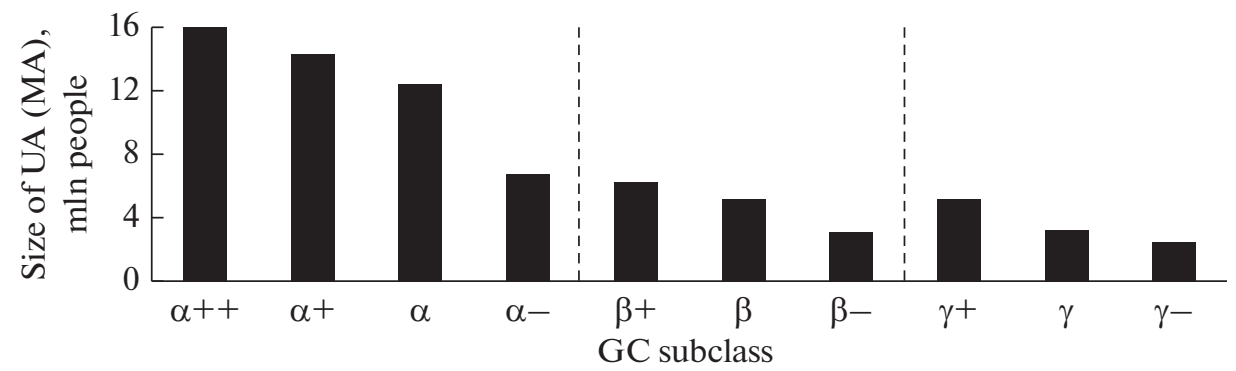

Fig. 6. Average size of urban or metropolitan areas corresponding to global cities, by class and subclass.

at this frontier, competition and the race for catch-up development are intensified, for which not the richest countries and centers need a larger size.

There are two times less countries with global cities on the list than the GCs themselves. The United States has 29, China has 24, and India, Germany, and Great Britain have 7-8 GCs. Russia and 15 other countries have two each, and 78 countries have one. Comparing this rating of countries (Fig. 7) with a similar one in UA (see Fig. 3), one can see a permutation in the pair of leaders, USA and China, but here, without a sharp gap between them. The global positions of the Third

\footnotetext{
${ }^{12}$ In this case, GCs are assigned either UAs or (if they are absent among 1055 UAs larger than $0.5 \mathrm{mln}$ people) MA with population according to other sources.
}

World are weaker, while those of the First World are stronger due to the GCs of Europe, Australia, and Canada instead of the USs from Asia and Africa in the corresponding list.

The same is indicated by comparison of Figs. 4 and 8, where the cluster of European GCs is dense enough. Asian and African UAs, despite their size, are not gaining in global "weight." Asia hosts half of all UAs and less than a third of GCs (although their total population is almost the same); the share of Africa is several times less, but higher than the share of Europe, Oceania, and North America, the regions with a high "global index" of large cities (Kurasov, 2009). In the proportion of centers of class a, they stand out even more, concentrating $60 \%$ of them (Table 2 ).

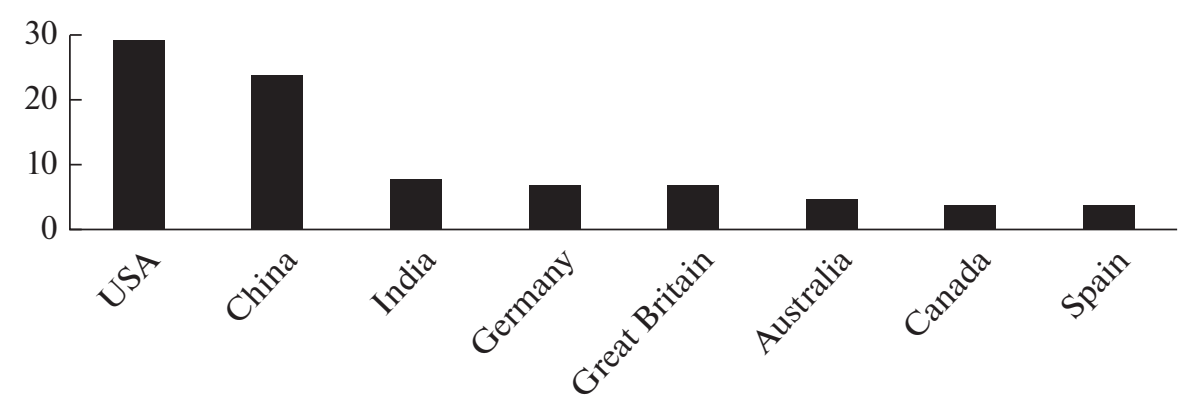

Fig. 7. Number of global cities in leading countries. 


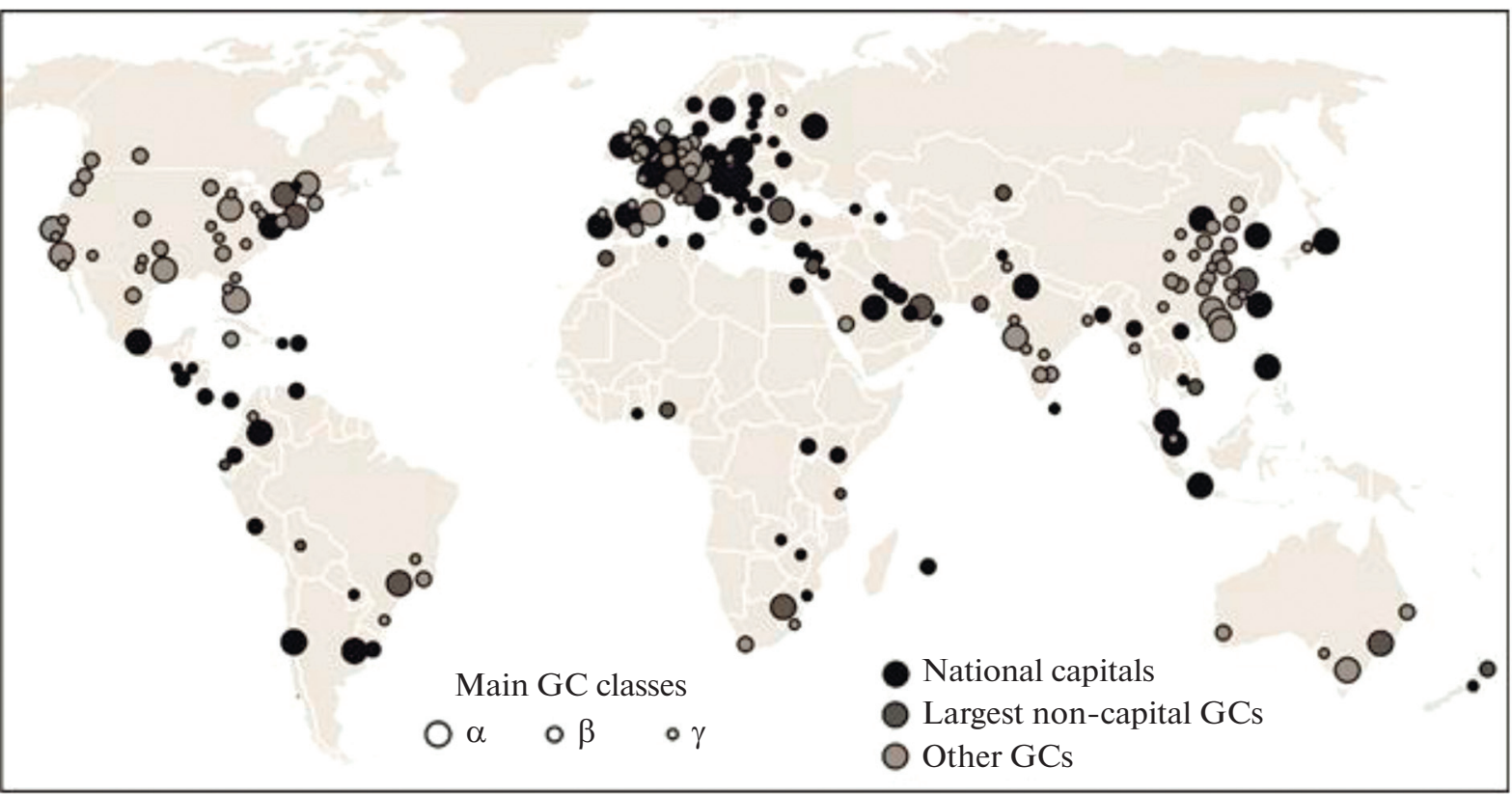

Fig. 8. Global cities in 2018 and national leaders among them.

Suspicion involuntarily arises that GaWC experts have resorted to some tricks in favor of Western GCs. However, one of the attempts to form a European fragment of the GC network according to broad traditional criteria, including the size of the population and the gross product of MA, their political and business functions in spheres other than business services, and their communications capacities, gave an unexpected result (Kurasov, 2009). An alternative network is less loyal to the capitals of Eastern Europe, offering instead centers of developed countries, and in general, differing little from the GaWC network. The experiment showed that it is not so easy to "stretch" the desired result.

Among the 209 GCs, there are 87 capital cities; their share is $42 \%$. They converge better in this respect than the world lists of UAs and capitals. The largest informal leaders of the countries add, as in the case of the UA, about 10 cities. Not all countries are able to grow at least one global center, and if a small and poor country is able to, then most often using its "absolute" capital of the 1st type. Much depends on the political, economic, and geographical conditions. There are more GCs based on capitals in places with a fractional political map, in medium and small countries, medium- and underdeveloped countries, where so much is spent on GCs that other cities remain underfunded. The monopoly of their capitals worsens their global chances. Large and powerful countries, especially English-speaking immigrant nations, are prone to polycentrism. The role of administrative and political rent in their development is lower; large cities and GCs are less often centers of the main regions. Even in China, not all GCs, including those of high classes,

Table 2. Global cities and large urbanized areas by regions of the world, 2018-2019, \%

\begin{tabular}{l|c|c|c|c}
\hline \multirow{2}{*}{ Region } & \multicolumn{2}{|c|}{ GC (total 209) } & \multicolumn{2}{c}{ UA (total 210) } \\
\cline { 2 - 5 } & Number & Population* & Number & Population \\
\hline World & 100.0 & 100.0 & 100.0 & 100.0 \\
Asia** & 32.5 & 52.7 & 49.8 & 56.4 \\
Europe*** $_{\text {North America**** }}^{28.2}$ & 13.1 & 8.6 & 7.7 \\
South America & 21.0 & 16.3 & 13.4 & 12.7 \\
Africa & 7.2 & 8.7 & 10.5 & 9.1 \\
Oceania & 7.7 & 7.8 & 16.7 & 13.5 \\
\hline
\end{tabular}

*Within UA; ** including Istanbul; *** including Russia; **** including Central America and Caribbean. 
serve as provincial centers and compete successfully with them due to the status of a special zone or lack thereof (Shenzhen, Chengdu, Hangzhou, Dalian, Suzhou, Xiamen, etc.). It is difficult to imagine this in Russia or a number of other countries with more modest potential, but strong centralization of power and spatial development.

Within a city, its global and metropolitan features are usually represented by the historical and/or business center. It is often emphasized by skyscrapers, rearing over ordinary buildings. Such external symbols are important for government and business, for demonstrating their success, and for the development of external relations. At the same time, all parts of a city are connected by many threads that ensure its unity and well-being.

The accumulation of GCs in three arenas of globalization-North America, Europe, and Asia-Pacifichas been noted by different authors. However, their concentration on a number of grounds is lower than that revealed for UAs. There is a closer match with the network of national capitals due to less penetration of GCs into the giant countries of Asia and more into Europe, where there are many capitals and GC, which coincide here more often than the world average.

\section{URBAN NETWORKS IN THE MIRROR OF CENTROGRAPHY}

Calculated geographic centers are essentially spatial averages, not values; rather, they are average locations of points, usually weighted by size. Although it is not a linear statistic, mathematically, the geocenter can also be arithmetic (center of gravity), geometric (center of convergence), and median (with equal populations to the north or south, west or east of it). Such a center is often "fictitious as a material point, but effective as a very laconic scientific abstraction that characterizes the distribution of the masses of the studied phenomenon in a given territory" (Polyan, 2014, p. 181).

The center of the world's land is found in Saudi Arabia, Egypt or Turkey. The scatter can be caused by disparate initial areas (with or without Antarctic, etc.), the types of center, and search methods. The median center of the world's population and most countries is given by the obscure source @ nailrkaye. ${ }^{13}$ The details have not been disclosed, but if the author is to be believed, the center is located near the Indian city of Udaipur. The center of convergence-the closest point for all humans-was fixed by the French demographic institute INED in the depths of Asia, at the borders of Kazakhstan, China, and Kyrgyzstan. ${ }^{14}$ It is also diffi-

\footnotetext{
${ }^{13}$ Center of population for each country in the world, Vivid Maps, October 9, 2019. https://vividmaps.com/centre-of-population.

${ }^{14}$ Center of World Population / CityExtremes. http://cityextremes.com/centerofpopulation. Accessed September 07, 2020.
}

cult to clarify the method and date, while the higher latitude is apparently associated with orthodromy.

The centers of the already considered networks of cities should be now identified. The business or historical cores of UAs, often combined, are taken as initial points, and if there are several cores, a point between them. The coordinates of the centers of gravity are determined by the formula of (Weinberg, 1915) for a sphere; it simplifies the shape of the Earth, but on the other hand, also calculation. Initially, they were found for the three size groups of UAs and were located along the Tropic of Cancer; the larger the group, the farther east (Fig. 9).

For cities of $1-5 \mathrm{mln}$ people in size ( 423 with a total population of $885 \mathrm{mln}$ people), the center was found on the border of Libya with Chad. For fiftythree UAs, the domiciles of 5-10 mln people (total $368.5 \mathrm{mln}$ people), it fell on the bend of the Nile near the Sudanese city of Abu Hamad, and for thirty-five UAs larger than $10 \mathrm{mln}$ people $(624 \mathrm{mln})$, in the Arabian Sea near Cape El-Hadd (Oman).

Dynamic centrograms are more informative: movement of the centers, as D.I. Mendeleev wrote (1906-1907), indicates the direction of many forces in a country. Long-term UA data series are lacking for this, although it is clear that their centers drifted to the southeast. The center of the 15 leading agglomerations in 1950, when nine of them belonged to Western countries, according to our calculations, was located in the Ionian Sea off the coast of Italy.

The center of gravity for the GCs populations lies on the tropic east of Mecca and Medina; by GC class, the centers fit so tightly (for $a$, slightly more southeast than for $\beta$ and $\gamma$ ) that it makes no sense to show them. The center of exactly the same number of capitals of completely sovereign and several semi-independent states partially acknowledged in the world, taking into account the size of UA or MA, "slips" south of Mecca. In 1950, when the number of countries and capitals was twice as little, ${ }^{15}$ their center was in northeast Libya. If we consider the capitals conditionally equal and ignore their sizes, then the center of the network of points not weighted by population, in the absence of metropolitan human anthills of South and East Asia, will be at nearly the same longitude, but to the south, in Chad (near the center of UAs with $1-5 \mathrm{mln}$ people), owing to the capitals of microstates in the tropics, in particular, on islands there.

Figure 10 shows the drift of the centers in four countries (giant cities proper and all residents in the United States and Russia, and MAs in India and China). In million-plus US cities, according to the author's calculations, it kept to the track of the center of the population as a whole (according to the US Census Bureau), lagging behind it in the 20th century,

\footnotetext{
${ }^{15}$ However, such now extinct states as Free Trieste, Sikkim, and the Republic of South Maluku did exist.
} 


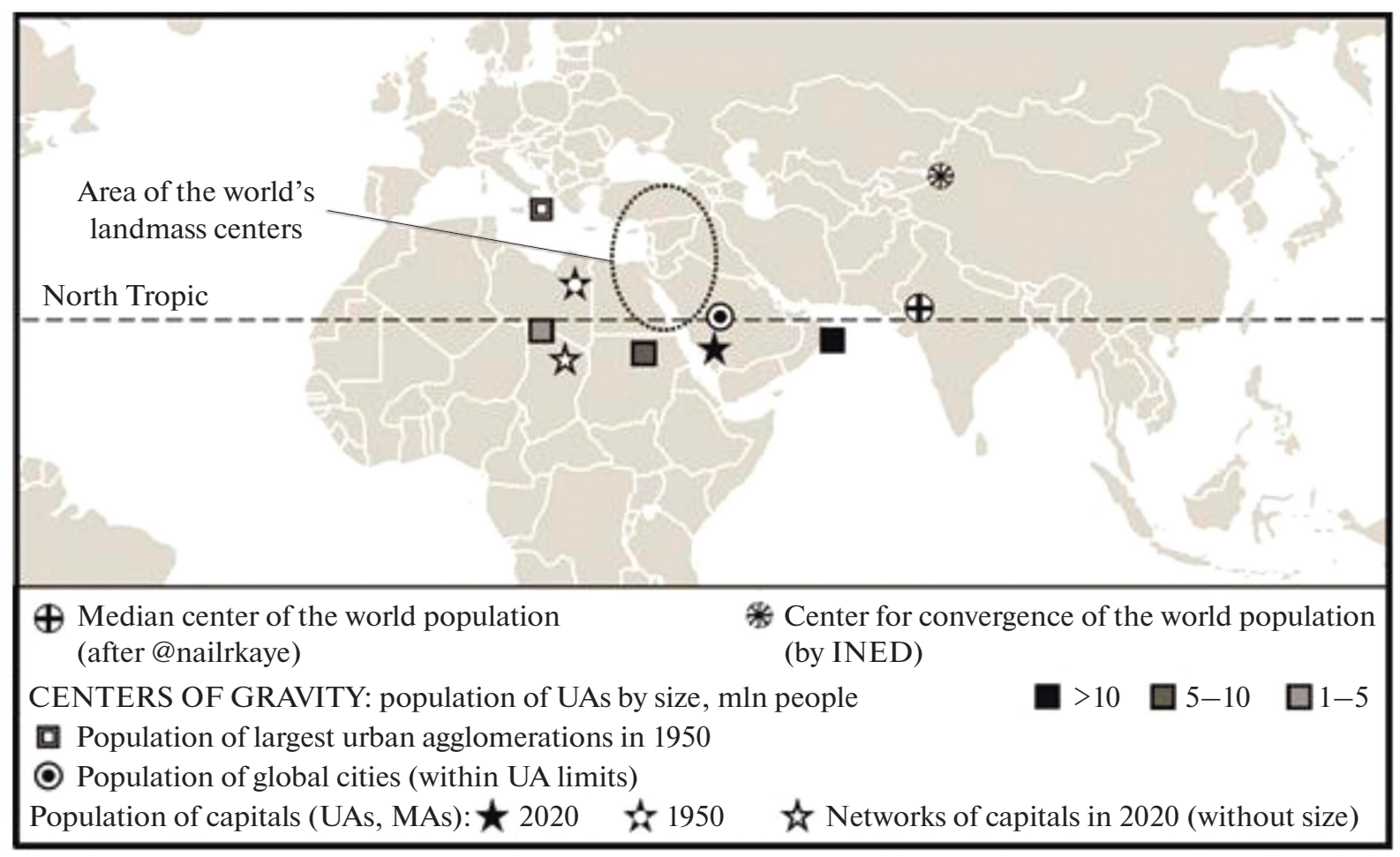

Fig. 9. Selected geographic centers of world population and leading cities.

and in the 21st century, outstripping in movement to the southwest, towards Texas. In Russia, such a center lags behind despite the leaps of the 1960s-1970s. The shift to the east was interrupted by the 1990s: the center backed up, circled, and in the 2010s, when Krasnoyarsk gained $1 \mathrm{mln}$ people, it again moved forward, but no farther than the Soviet one. The center of the population is located $600 \mathrm{~km}$ southeast and is moving away to the southwest from the White River in Bashkiria after 1989 (as well as the center of gravity of townspeople and village residents). The Indian million-plus agglomeration center's drift since 1950 is similar in direction, but not in magnitude, to the American center, gradual with an increase in the southern moment. In China, the change in trajectory is even more pronounced than in Russia. Under Mao Zedong, the center moved north towards Beijing, and in the past 40 years it has surged $350 \mathrm{~km}$ south, southwest, and towards Wuhan (this birthplace of the coronavirus is in the thick of Chinese urban poles).

Thus, the centers of the leading cities of the two countries, which have survived a change in regimes in the broadest sense of the word, have shown a breakdown in direction and pace, but in different ways, adequate to economic dynamics. In India and the United States, there were no such ordeals, and the centers went westward, gradually turning to the south. The southern component makes all cases related. There are few of them, but it seems that the global shift to the south, in addition to the change in the proportions of the "large" North and South, is due to shifts in the "sun belts" within some large countries.

\section{CONCLUSIONS}

The conducted analysis makes it possible to concisely formulate the following main findings.

(1) The global network of largest cities, taken within the framework of urbanized areas, differs (including from the networks of most countries) in polycentrism; its leaders change, competing, catching up, and overtaking each other. This coincides with the network of national capitals only by a third because of their different nature: there is usually one capital in each country, but there can be several, even dozens of large cities.

(2) Much depends on the size and type of the country. The largest (and richest) countries are characterized by bi- and polycentrism, with active competition between leaders; the most striking exceptions among the giants are Indonesia and Russia. Smaller and poorer countries are more likely to be monocentric. The role of capitals is frequently higher there, although it is growing rapidly even in such polycentric giant countries as India and China.

(3) The networks of global and simply large cities are more closely overlapped: by $60 \%$. The relationship between GCs and national capitals is also more noticeable. However, it also depends on the type of country, the traditions of polycentrism or monocen- 

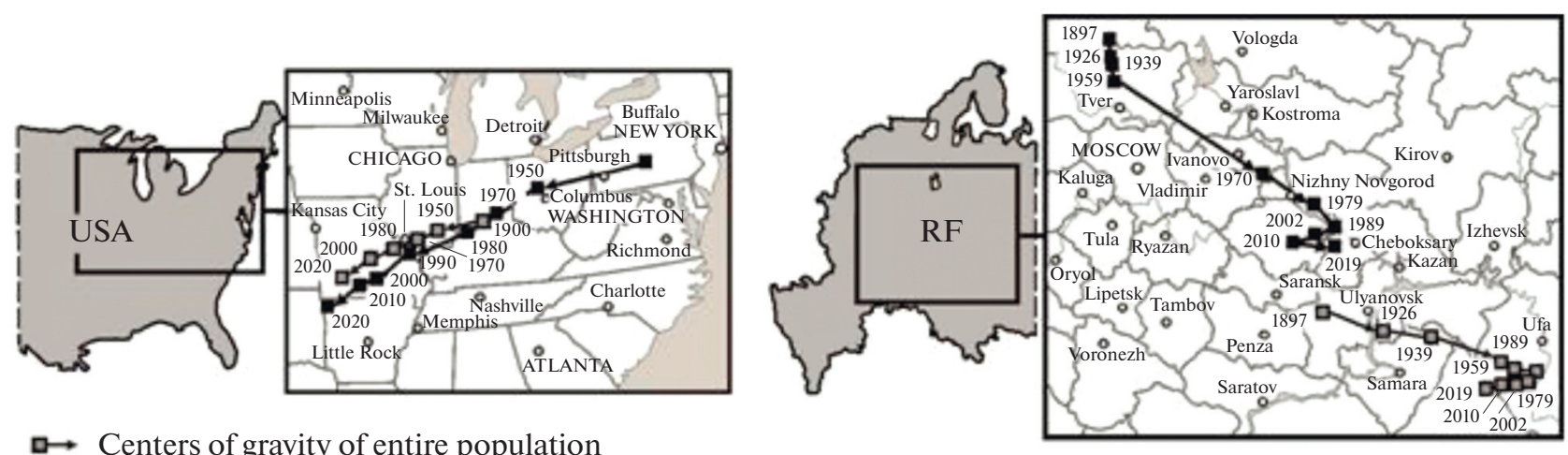

$\square \rightarrow$ Centers of gravity of entire population

$\rightarrow$ Centers of gravity of populations in cities exceeding $1 \mathrm{mln}$ people
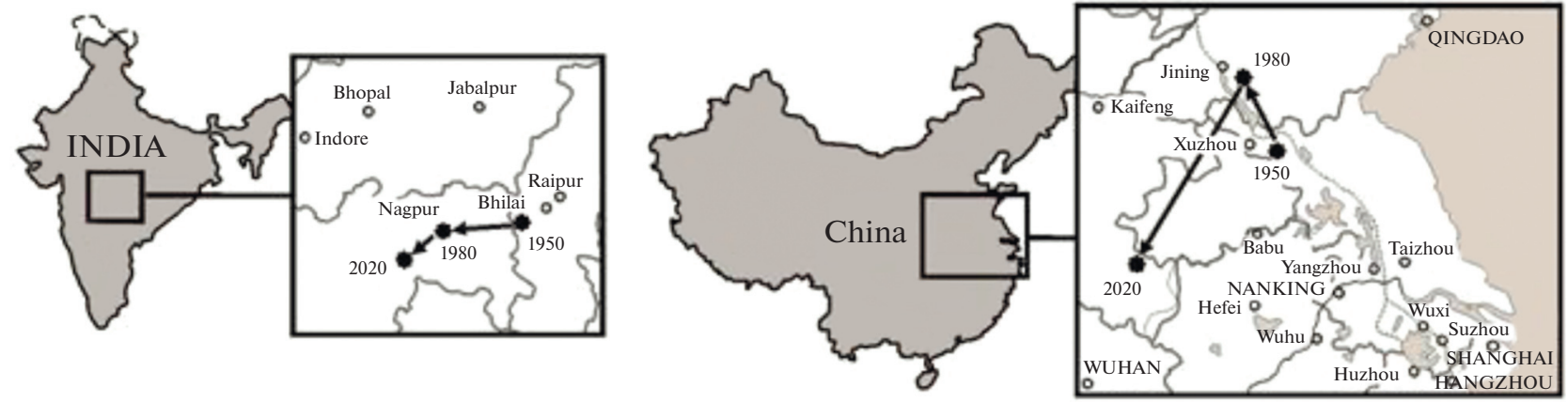

$\bullet$ Centers of gravity of urban agglomerations exceeding $1 \mathrm{mln}$ people

Fig. 10. Shifts in selected population centers in four countries.

trism, and the different weight of political rent in spatial development.

(4) The indisputable shift of global urban networks to the south is caused not only by global, but seemingly also by intranational processes of the same geographical direction, sometimes amid sharp change in the vector of interregional and intercity shifts in countries with transitional economies (China and Russia).

This article is limited in scale. It is devoted specifically to the global networks of leading cities and only partially, in the form of examples, national ones. The forces driving them, urban phenomena, etc., are remarked on in passing or parenthetically. The author has attempted to compare the main properties of the selected upper parts of global urban rankings and, if possible, trace their spatial movement. Everything else is a subject of other studies and authors.

\section{FUNDING}

The article was prepared under the state-ordered research theme of the Institute of Geography RAS (no. 0148-2019-0008 "Problems and Prospects of Russia's Territorial Development under Conditions of Its Unevenness and Global Instability”).

\section{CONFLICT OF INTEREST}

The author declares no conflict of interest.

\section{REFERENCES}

Capital Cities and Urban Sustainability, Orttung, R.W., Ed., London: Routledge, 2019.

Glezer, O.B., Kolosov, V.A., Brade, I., Coudroy de Lille, L., and Sluka, N.A., Integrated forms of urban settlement pattern in Russia, Europe, and worldwide, Reg. Res. Russ., 2014, vol. 4, no. 2, pp. 80-89.

Kurasov, A.V., Development of global cities in different geographic conditions, Extended Abstract of Cand. Sci. (Geogr.) Dissertation, Moscow, 2009.

Lappo, G.M., Geografiya gorodov (Geography of Cities), Moscow: VLADOS, 1997.

Massey, D., Imagining globalization: power-geometries of time-space, in Global Futures: Migration, Environment and Globalization, Brah, A., , Eds., London: Macmillan, 1999, pp. 27-44.

Mendeleev, D.I., K poznaniyu Rossii (Study of Russia), St. Petersburg: Izd. A.S. Suvorina, 1906-1907.

Moreno-Monroy, A., Schiavina, M., and Veneri, P., Metropolitan areas in the world. Delineation and population trends, J. Urban Econ., 2020, art. ID 103242. https://doi.org/10.1016/j.jue.2020.103242

Moskovskii stolichnyi region: territorial'naya struktura $i$ prirodnaya sreda. Opyt geograficheskogo issledovaniya (Moscow Metropolitan Region: Territorial Structure 
and Nature Environment. Geographical Research Experience), Moscow: Inst. Geogr., Akad. Nauk SSSR, 1988.

Okunev, I.Yu., Stolitsy $v$ zerkale kriticheskoi geopolitiki (Capitals in Reflection of Critical Geopolitics), Moscow: Aspekt Press, 2020.

Polyan, P.M., Territorial'nye struktury - urbanizatsiya rasselenie: teoreticheskie podkhody i metody izucheniya (Territorial Structures - Urbanization - Settlement Pattern: Theory and Practice), Moscow: Novyi Khronograf, 2014.

Rossman, V., Capital Cities: Varieties and Patterns of Development and Relocation, London: Routledge, 2016.

Taylor, P.J., World City Network: A Global Urban Analysis, London: Routledge, 2003.
Treivish, A.I., Gorod, raion, strana i mir. Razvitie Rossii glazami stranoveda (City, Region, Country, and the World. Development of Russia as Viewed by a Regional Geographer), Moscow: Novyi Khronograf, 2009.

Treivish, A.I., Capital cities and state borders: spatial relationships and shifts, Reg. Res. Russ., 2016, vol. 6, no. 3, pp. 244-257.

Treivish, A.I., Zotova, M.V., and Savchuk, I.G., Types of cities in Russia and across the globe, Reg. Res. Russ., 2014, vol. 4, no. 2, pp. 90-94.

Veinberg, B.P., Positions of the center of Russia from the beginning of the Principality of Moscow to the present. Positions of the center of Russia's population from 1613 to 1913 , Izv. Imp. Russ. Geogr. O-va, 1915, vol. 51, no. 6, pp. $365-408$. 